\title{
Towards the acoustic estimation of jellyfish abundance
}

\author{
Andrew S. Brierley, ${ }^{1, *}$, David C. Boyer ${ }^{2,6}$, Bjørn E. Axelsen ${ }^{3}$, Christopher P. Lynam ${ }^{1}$, \\ Conrad A. J. Sparks ${ }^{4}$, Helen J. Boyer ${ }^{2}$, Mark J. Gibbons ${ }^{5}$ \\ ${ }^{1}$ Gatty Marine Laboratory, University of St. Andrews, Fife KY16 8LB, UK \\ ${ }^{2}$ National Marine Information and Research Centre, PO Box 912, Swakopmund, Namibia \\ ${ }^{3}$ Institute of Marine Research, PO Box 1870 Nordnes, 5817 Bergen, Norway \\ ${ }^{4}$ Faculty of Applied Sciences, Cape Technikon, PO Box 652, Cape Town 8000, South Africa \\ ${ }^{5}$ Zoology Department, University of Western Cape, Private Bag X 17, Bellville 7535, South Africa
}

${ }^{6}$ Present address: Fisheries \& Environmental Research Support, Orchard Farm, Cockhill, Castle Cary, Somerset BA7 7NY, UK

\begin{abstract}
Acoustic target strengths (TSs) of the 2 most common large medusae, Chrysaora hysoscella and Aequorea aequorea, in the northern Benguela (off Namibia) have previously been estimated (at 18, 38 and $120 \mathrm{kHz}$ ) from acoustic data collected in conjunction with trawl samples, using the 'comparison method'. These TS values may have been biased because the method took no account of acoustic backscatter from mesozooplankton. Here we report our efforts to improve upon these estimates, and to determine TS additionally at $200 \mathrm{kHz}$, by conducting additional sampling for mesozooplankton and fish larvae, and accounting for their likely contribution to the total backscatter. Published sound scattering models were used to predict the acoustic backscatter due to the observed numerical densities of mesozooplankton and fish larvae (solving the forward problem). Mean volume backscattering due to jellyfish alone was then inferred by subtracting the model-predicted values from the observed water-column total associated with jellyfish net samples. Zooplankton-corrected echo intensity/jellyfish density data pairs were in close agreement with linear relationships determined previously from uncorrected data. Small sample sizes precluded recalculation of TS, but nonparametric pair-wise tests failed to detect any significant differences between echo intensities for jellyfish densities observed in the present study and echo intensities predicted for those densities by density-intensity relationships arising from the previous study. Previous linear density-intensity relationships had $y$-axis intercepts greater than zero. On the assumption that the positive intercepts were due to backscatter from unsampled mesozooplankton, new TS relationships were calculated from downward-adjusted density-intensity relationships. New values agreed closely with TS estimates determined elsewhere using single-target echo detection techniques. Given that estimates of jellyfish TS appear robust, it should now be feasible to identify jellyfish acoustically at sea and to assess their abundance, even in the presence of mixed mesozooplankton assemblages.
\end{abstract}

KEY WORDS: Aequorea aequorea · Chrysaora hysoscella · Forward problem • Jellyfish · Multi-frequency $\cdot$ Target strength $\cdot$ Zooplankton

\section{INTRODUCTION}

Jellyfish are gaining increasing prominence in many pelagic marine ecosystems worldwide (Mills 2001, Kideys 2002, Xian et al. 2005). It has been argued that jellyfish-dominated communities will be the end-point in ecosystems perturbed by high fishing effort (Pauly et al. 1998, 2002), and that increases in jellyfish abundance could be indicative of climate-induced changes and/or regime shifts in pelagic ecosystems (Brodeur et al. 1999, Lynam et al. 2004, 2005a,b, Purcell \& Decker 2005). Jellyfish may also have adverse impacts on com- 
mercially important fish species, either directly by predation on larval stages or indirectly via competition for food (Schneider \& Behrends 1998, Purcell \& Arai 2001, Purcell \& Sturdevant 2001, Sommer et al. 2002, Lynam et al. 2005a). For a variety of reasons, therefore, there is a requirement to be able to estimate jellyfish abundance robustly and to map jellyfish distribution at sea.

Acoustic surveys provide a powerful means for sampling pelagic organisms including fish and crustacean mesozooplankton. In order for acoustic observations to be translated into species biomass, however, knowledge of the acoustic properties of the target organisms is required. Acoustic target strength (TS) quantifies the proportion of incident sound energy at a given frequency backscattered from an object, and is the key parameter required in conversion of acoustic survey data to estimates of species abundance. This study sought to determine TS values at multiple frequencies $(18,38,120$ and $200 \mathrm{kHz})$ for the 2 most common large medusae in the northern Benguela: the scyphozoan Chrysaora hysoscella and the hydrozoan Aequorea aequorea. A previous study has attempted to estimate TS values for these jellyfish at sea (Brierley et al. 2001), but may potentially have been compromised by failure to take account of echoes arising from other watercolumn mesozooplankton. Weight for weight, nongelatinous zooplankton are likely to be substantially stronger acoustic targets than gelatinous plankton (Stanton et al. 1996), and echoes from jellyfish could potentially be masked in 'noise' from mesozooplankton. In this study we sampled specifically for nongelatinous mesozooplankton and fish larvae using dedicated nets, and used published sound scattering models to predict echo intensities that would arise from the observed numerical densities of mesozooplankton. Our approach, using 'forward' models to account for the contribution to total integrated water column echo intensity from non-gelatinous mesozooplankton, enables the backscatter from jellyfish to be isolated.

\section{MATERIALS AND METHODS}

This study was designed to extend a previous series of observations by Brierley et al. (2001) who used the 'comparison method' to infer the acoustic TS of jellyfish in the northern Benguela. Their method sought to correlate integrated water-column acoustic backscatter with numerical densities of jellyfish, as estimated by net sampling, in order to determine the echo intensity from single jellyfish. A weakness of their approach was that the large-meshed nets required to sample jellyfish did not retain mesozooplankton, and it was therefore impossible for them to determine what proportion of the total integrated echo energy was due to targets other than jellyfish. This in turn may have lead to biased TS estimates. In order to overcome this weakness, the present study included a dedicated finemeshed mesozooplankton netting and sample-analysis component.

Sampling protocol. All sampling was conducted in the northern Benguela from the FRV 'Dr. Fridtjof Nansen' between 2 and 5 September 2001. Acoustic data were collected continuously throughout this period. Two stations were occupied, both of which were at approximately $22^{\circ} \mathrm{S}$. The first station was situated near-shore between the 75 and $135 \mathrm{~m}$ isobaths. The second was on the mid-shelf in the vicinity of the $250 \mathrm{~m}$ depth contour. Two stations were worked because previous experience had shown an acrossshelf separation in the distribution of the 2 target species, with Aequorea aequorea being found further offshore than Chrysaora hysoscella (Buecher et al. 2001, Sparks et al. 2001). At each station a cycle of samples consisting of consecutive deployments of a mid-water trawl net to sample jellyfish and fish, a multinet haul to sample non-gelatinous mesozooplankton, and a CTD cast was conducted.

Jellyfish net sampling. Jellyfish were sampled using a modified Åkrehamn pelagic trawl ( $12 \mathrm{~m}$ vertical opening) fitted with a multisampler system (Skeide et al. 1997). The multisampler comprised 3 separate cod ends (22 $\mathrm{mm}$ mesh) that could be opened sequentially by acoustic command, enabling 3 discrete samples to be taken (at discrete depth or time intervals). The system failed on several occasions, usually due to excessive jellyfish catches, and during the period that it took to make repairs a Super Gisund bottom trawl with a vertical opening of $5 \mathrm{~m}$ was used to sample jellyfish in the pelagic zone. For both nets, the volume sampled was calculated as the area of the net opening, assuming a circular opening with a diameter equal to the vertical opening, multiplied by the distance trawled. Typical sampling time was $5 \mathrm{~min}$, which at a speed of about $1.5 \mathrm{~m} \mathrm{~s}^{-1}$ corresponded to an along-track distance of $450 \mathrm{~m}$. Following net recovery, the catch was sorted, subsampled where necessary, and the numbers and sizes of captured organisms measured. A total of 72 pelagic net samples were obtained during the $5 \mathrm{~d}$ cruise.

Zooplankton sampling and analysis. Following each jellyfish trawl, a Hydrobios multinet system was used to sample mesozooplankton from the section of the water column as close as possible to that sampled by the jellyfish multisampler. The Hydrobios system consisted of 5 acoustically controlled opening and closing nets ( $405 \mu \mathrm{m}$ mesh) mounted on a $0.5 \times 0.5 \mathrm{~m}$ square frame. The net was fished to sample the water column obliquely in adjacent vertical intervals from the nearbottom to the near-surface, and sampled the depth horizon previously sampled by the pelagic trawl. The 
volume sampled was determined by multiplying the mouth opening area by the distance sampled, as determined by Hydrobios flow meters mounted in the mouth of each net. Captured mesozooplankton were preserved in buffered formalin for subsequent laboratory analysis.

In the laboratory, sub-sampling was undertaken to provide manageable sample sizes. Within subsamples, all organisms were counted and identified, and random samples were measured to $0.1 \mathrm{~mm}$ to provide size-frequency distributions. Taxon-specifc size measurements were as follows: prosome length for copepods; rostrum to telson length for euphausiids, decapods, stomatopods, mysids and amphipods; head to caudal fin for chaetognaths; snout to caudal fin for fish larvae; maximum gas bladder dimension for physonects; anterio-posterior length for polychaetes and pteropods; anterior/posterior bell height for calycophoran siphonophores.

Acoustic sampling and data processing. Two Simrad EK500 echosounders, operating at frequencies of 18, 38 and 120 and $200 \mathrm{kHz}$, were run continuously throughout the cruise at a ping rate of 0.5 pings $\mathrm{s}^{-1}$. Data were logged using Echolog_EK (SonarData). The echosounders were calibrated at all frequencies immediately after the sampling cruise. Calibration corrections and all other acoustic post-processing was conducted using SonarData Echoview. Calibration-corrected acoustic data at each frequency were resampled onto a 10 ping horizontal $\times 1 \mathrm{~m}$ vertical grid. TVG (time varied gain) amplified noise was removed from the resampled data by subtracting a generated $20 \log (r)+2 \alpha(r)$ function (Watkins \& Brierley 1996), where $r$ is range and $\alpha$ is a frequency-specific sound absorption rate.

Sections of echogram corresponding to the water column sampled by each trawl were identified using knowledge of the length of trawl-warp required to fish the net at a given depth, and the associated time/space offset between the echosounder transducers and the net. Regions of echograms corresponding to trawl samples were integrated to provide a value of total backscatter (evaluated as nautical area scattering coefficient (NASC) $\mathrm{m}^{2} \mathrm{n}$ mile $^{-2}$ ) at all 4 frequencies for each trawl.

Trawl-data quality assurance. The first step toward linking integrated echo intensity to trawl-detected jellyfish density was to identify those trawls where jellyfish dominated the catch and hence where echoes from non-gelatinous nekton such as fish were unlikely to have contributed substantially to total backscatter. Samples were only accepted for further analysis if the proportion by weight of Aequorea aequorea was greater than $95 \%$, or Chrysaora hysoscella $>70 \%$. All trawl samples that contained more than $0.25 \%$ by weight of fish were excluded from further analysis. Second, we wished to be able to account for the pro- portion of total integrated echo energy likely to be caused by mesozooplankton. Our philosophy was to assume that, given certain provisos, the mesozooplankton community sampled by the multisampler deployment following the pelagic trawl was likely to be representative of the mesozooplankton community in the body of water sampled by the pelagic trawl. However, zooplankton distributions are notoriously patchy both in space and time. Thus the spatial and temporal separation between paired zooplankton and jellyfish net samples had to be minimised if our assumption was to remain valid. Therefore we excluded from our analyses those jellyfish trawl samples for which the paired zooplankton sample was taken more than $4 \mathrm{n}$ miles away from, or more than $3 \mathrm{~h}$ after, the jellyfish trawl. We also excluded samples where clear evidence of diel vertical migration of the acoustic scattering layers made it likely that there were differences in vertical plankton distributions between the jellyfish- and plankton-trawls (in practical terms this meant exclusion of pelagic-zooplankton trawl pairs that spanned dawn or dusk).

Zooplankton modelling: solving the forward problem. In order to link trawl-related echo intensity to trawl-derived jellyfish density it was necessary to subtract from the total integrated trawl-backscatter-value the contribution at each frequency likely to be due to mesozooplankton. Likely echo intensities at each frequency for individual plankters were calculated using published scattering models appropriate for each zooplankton species. The models we used are listed in Table 1. All models required assumptions about the material properties of the organisms to be made. Particularly, values for $g$ (the ratio of the density of the organism to the density of sea water) and $h$ (the ratio of the speed of sound in the organism to the speed in sea water) were required. The literature is replete with studies of $g$ and $h$ for mesozooplankton (e.g. Greenlaw 1979, Stanton et al. 1994, Trevorrow \& Tanaka 1997) and we opted to use median values from the literature (1.04 for both). We assumed that the main soundscattering structure for physonect larvae (class Siphonophora) was the gas-filled bladder (cf. Benfield et al. 2003). Following Coyle (2000) we assumed that sound scattering from larval fish would be due to the swim bladder alone, and that the swim bladder diameter would be $9 \%$ of the fish length. Scattering from both physonect air bladders and fish swim bladders was modelled using the Stanton et al. (1994) gas sphere high pass model. All models were parameterised with a sound velocity in water of $1504 \mathrm{~m} \mathrm{~s}^{-1}$ appropriate given local temperature and salinity conditions. The theoretical volume backscatter that would be expected from the numerical density of each species from each sampling volume was computed by 
summing the individual backscatters from observed densities of each taxon (in the linear domain) to give the total theoretical backscatter of mesozooplankton from the volume sampled. The procedure is similar to that described by Wiebe et al. (1996).

Linking jellyfish density to echo intensity. The total predicted zooplankton backscatter at each frequency was subtracted from the integrated total for the trawl in order to determine the total backscatter at each frequency due to jellyfish alone. Regression analyses were then performed to investigate possible relationships between jellyfish density and echo intensity at each frequency, and it was our intention to calculate jellyfish TS at each frequency from these relationships.

\section{RESULTS}

Of the 72 jellyfish trawl samples taken, 11 were considered invalid because either the net tore or the acoustic releases failed to operate properly. Thirty-two samples were discarded because the proportion of jellyfish in the catch was low, and a further 4 samples had high fish catches and were also excluded. Five samples were excluded because the 'paired' zooplankton sample was too remote from the jellyfish trawl, and a further 6 samples were excluded because the jellyfish-zooplankton trawl pairs spanned dusk or dawn. Following these stringent data quality controls, only 14 samples remained for analysis, 4 containing primarily Chrysaora hysoscella and 10 with Aequorea aequorea. Ideally we would have liked to consider samples where the jellyfish catch was zero in order to be able to comment upon error around the origin in our jellyfish density - acoustic intensity regressions. However, only 2 trawls had zero jellyfish catch and no other disqualifying biological factors (5 trawls had no jellyfish but significant quantities of fish; we were not convinced that the net provided unbiased samples of fish density) and these 2 trawls were instances when the net burst. The high rate of attrition from possible samples to useable samples is illustrative of the problems associated with net sampling for large medusae.

Numerical densities of jellyfish in the 14 valid pelagic trawls ranged from 0.0069 to 0.1148 individuals $\mathrm{m}^{-3}$ for Aequorea aequorea, and from 0.0002 to

Table 1. Various zooplankton taxa. Zooplankton sampled in the valid sample pairs, the model used to predict TSs (target strengths) per individual and the TSs at 4 frequencies for individuals of the given mean key dimension. See 'Materials and methods' for key dimensions

\begin{tabular}{|c|c|c|c|c|c|c|c|c|}
\hline Taxon & Model type & $\begin{array}{c}\text { Size, mm } \\
\text { Mean (SD) }\end{array}$ & $\begin{array}{l}\text { Density, } \mathrm{m}^{-3} \\
\text { Mean (SD) }\end{array}$ & $\begin{array}{l}\text { TS } 18 \\
\text { kHz dB }\end{array}$ & $\begin{array}{c}\text { TS } 38 \\
\mathrm{kHz} \mathrm{dB}\end{array}$ & $\begin{array}{l}\text { TS } 120 \\
\text { kHz dB }\end{array}$ & $\begin{array}{r}\text { TS } 200 \\
\text { kHz dB }\end{array}$ & Source \\
\hline $\begin{array}{l}\text { Alima } \\
\text { (Stomatopoda) }\end{array}$ & $\begin{array}{l}\text { Randomly oriented } \\
\text { fluid bent cylinder }\end{array}$ & $8.2(0.4)$ & $0.001(0.004)$ & -128.72 & -117.31 & -100.60 & -94.07 & Stanton et al. (1994) \\
\hline Chaetognaths & $\begin{array}{l}\text { Randomly oriented } \\
\text { fluid bent cylinder } \\
\text { adapted for long thin } \\
\text { shape }(16: 1)\end{array}$ & $13.8(1.4)$ & $3.798(3.960)$ & -129.83 & -118.43 & -101.46 & -94.67 & Stanton et al. (1994) \\
\hline Copepods & Simplified fluid sphere & $2.1(0.7)$ & $98.632(117.804)$ & -145.44 & -132.46 & -112.50 & -103.68 & Greenlaw (1979) \\
\hline Decapod larvae & $\begin{array}{l}\text { Randomly oriented } \\
\text { fluid bent cylinder }\end{array}$ & $0.8(0.2)$ & $0.002(0.007)$ & -180.78 & -171.60 & -155.43 & -147.71 & Stanton et al. (1994) \\
\hline Euphausiids (adults) & $\begin{array}{l}\text { Randomly oriented } \\
\text { fluid bent cylinder }\end{array}$ & $11.1(2.5)$ & $0.140(0.231)$ & -121.47 & -110.12 & -94.00 & -88.09 & Stanton et al. (1994) \\
\hline Euphausiids (furcilia) & $\begin{array}{l}\text { Randomly oriented } \\
\text { fluid bent cylinder }\end{array}$ & $3.8(1.3)$ & $0.211(0.470)$ & -146.88 & -135.74 & -118.27 & -110.86 & Stanton et al. (1994) \\
\hline Fish larvae & Gas sphere high-pass & $6.1(2.4)$ & $0.075(0.135)$ & -68.95 & -69.48 & -72.31 & -73.99 & Stanton et al. (1994) \\
\hline Hyperiid amphipods & Straight fluid cylinder & $3.7(1.8)$ & $4.090(10.969)$ & -130.50 & -117.58 & -98.49 & -91.25 & $\begin{array}{l}\text { Trevorrow \& } \\
\text { Tanaka (1997) }\end{array}$ \\
\hline Mysids & $\begin{array}{l}\text { Randomly oriented } \\
\text { fluid bent cylinder }\end{array}$ & $5.5(3.3)$ & $0.048(0.165)$ & -138.22 & -126.88 & -109.65 & -102.58 & Stanton et al. (1994) \\
\hline Ostracods & Spherical elastic shell & $1.2(0.3)$ & $0.016(0.024)$ & -125.87 & -112.89 & -93.01 & -84.74 & Stanton et al. (1994) \\
\hline $\begin{array}{l}\text { Pasiphaea } \\
\text { (Decapoda) }\end{array}$ & $\begin{array}{l}\text { Randomly oriented } \\
\text { fluid bent cylinder }\end{array}$ & $11.7(8.5)$ & $0.050(0.061)$ & -120.21 & -108.88 & -92.88 & -87.11 & Stanton et al. (1994) \\
\hline Physonect larvae & Gas sphere high-pass & $0.3(0.1)$ & $0.441(0.518)$ & -70.62 & -73.70 & -75.99 & -77.22 & Stanton (1989) \\
\hline Polychaete larvae & $\begin{array}{l}\text { Randomly oriented } \\
\text { fluid bent cylinder }\end{array}$ & $0.8(0.3)$ & $0.014(0.019)$ & -180.78 & -171.60 & -155.43 & -147.71 & Stanton et al. (1994) \\
\hline Polychaetes & $\begin{array}{l}\text { Randomly oriented } \\
\text { fluid bent cylinder }\end{array}$ & $4.8(3.1)$ & $0.032(0.049)$ & -141.43 & -130.14 & -112.80 & -105.59 & Stanton et al. (1994) \\
\hline Pteropods & Simplified fluid sphere & e $1.7(1.9)$ & $0.071(0.124)$ & -149.45 & -136.47 & -116.49 & -107.65 & Greenlaw (1979) \\
\hline Siphonophores & $\begin{array}{l}\text { Randomly oriented } \\
\text { fluid bent cylinder }\end{array}$ & $4.9(1.5)$ & $0.049(0.087)$ & -140.94 & -129.65 & -112.32 & -105.13 & Stanton et al. (1994) \\
\hline
\end{tabular}


0.0103 individuals $\mathrm{m}^{-3}$ for Chrysaora hysoscella. The A. aequorea inner umbrella diameter ranged from 5.0 to $8.5 \mathrm{~cm}$, with a mean of $6.6 \mathrm{~cm}(\mathrm{n}=1200)$, and the C. hysoscella umbrella diameter ranged from 10 to $61 \mathrm{~cm}$, with a mean of $37.9 \mathrm{~cm}(\mathrm{n}=153)$. Mean densities (and standard deviations) of mesozooplankton caught in the 14 valid paired samples are shown in Table 1, along with measures of size and modelestimates of their TS at the 4 frequencies. Plots of zooplankton-corrected integrated echo intensity against trawl-determined jellyfish numerical density are given in Fig. 1. Although all echo intensity-jellyfish density relationships appeared to be positive, regression analysis failed to detect any significant relationships for either species at any of the 4 frequencies, and it was not therefore possible to calculate TS for individual jellyfish from our new data. Visual inspection, however, suggested a strong similarity between the new corrected data and our previously published (Brierley et al. 2001) uncorrected comparison-method data. In order to investigate whether our new zooplankton-
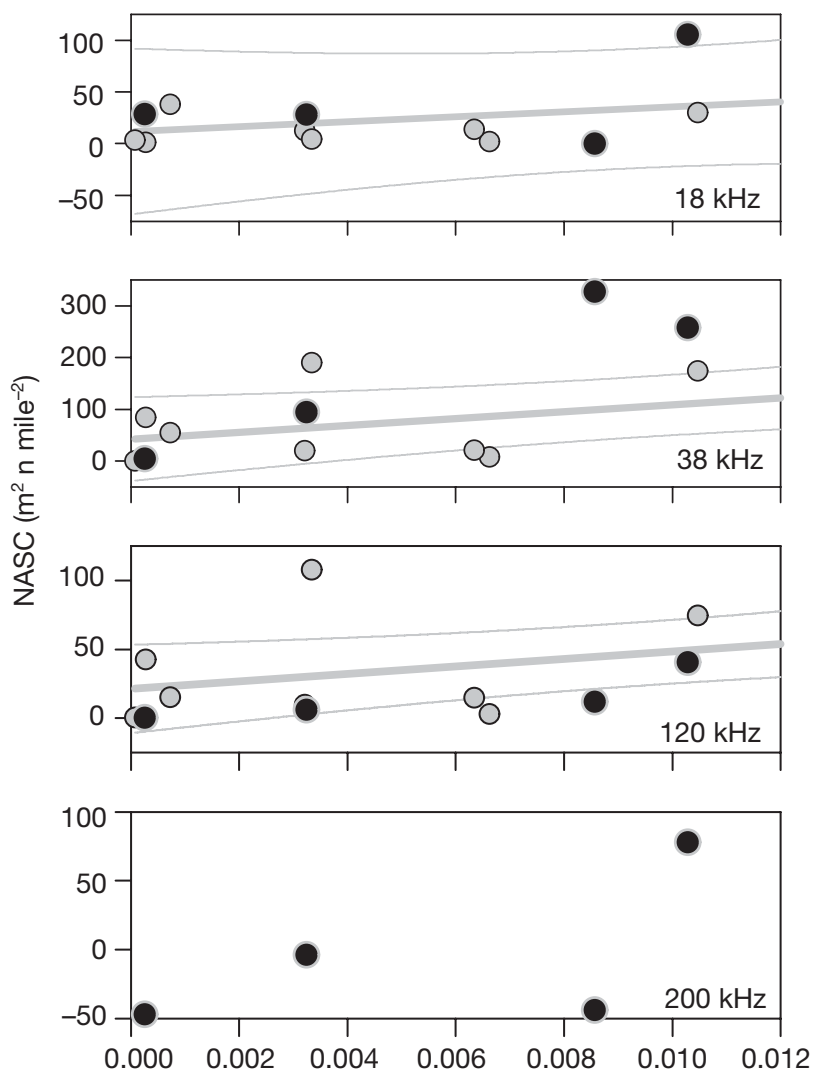

corrected acoustic data were significantly different from earlier uncorrected data (which would be expected if earlier data were biased significantly by a contribution from zooplankton) we conducted Wilcoxon Signed Rank tests between pairs of NASC values associated with jellyfish densities observed in the present study and NASC values predicted at those densities by the regression relationships between NASC and density determined in our previous study. These tests revealed no significant differences.

\section{DISCUSSION}

Although 72 targeted pelagic trawls for jellyfish were conducted throughout the course of this study, application of stringent data quality controls left only 14 for subsequent analysis. This small sample size, allied to the difficult task of linking acoustic and net data collected nominally from the same water mass but which was in fact blurred by the spatio-temporal
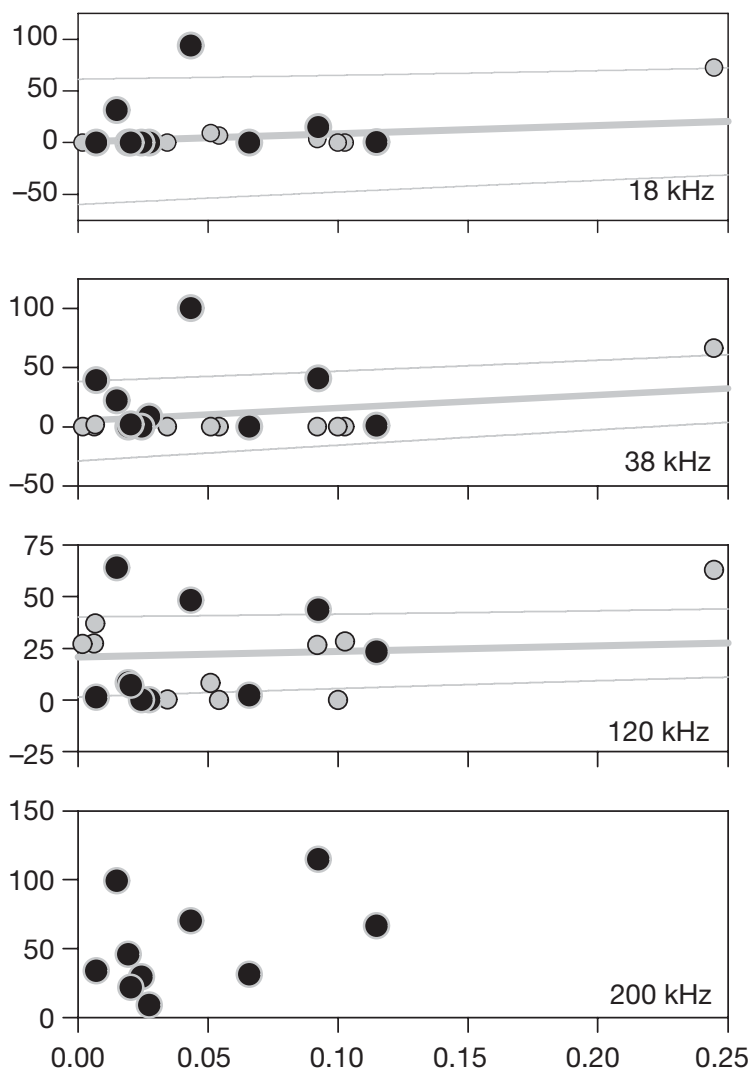

Volume density, (ind. $\mathrm{m}^{-3}$ )

Fig. 1. Chrysaora hysoscella and Aequorea aequorea. Relationships between volume density of jellyfish and acoustic backscatter as quantified by the nautical area scattering coefficient (NASC). Left-hand panels: C. hysoscella; right-hand panels: A. aequorea. Black points are data from the present study with NASC values model-corrected for mesozooplankton contributions. Grey points are data from Brierley et al. (2001) and the lines are linear regressions (and $95 \%$ confidence limits) through their data 
heterogeneity inherent with mobile organisms inhabiting a fluid environment, has left us unable to construct significant jellyfish density-echo intensity relationships.

In addition to the problems associated with attempts to link net samples and water-column echo integration values in space and time, our approach to modelling expected backscatter from zooplankton has been simplistic. Rather than simply calculate a single TS value from a mean size of a particular zooplankton and raise this to a volume backscattering estimate for a mean numerical density, it would have been more elegant to calculate distributions of TS for the range of sizes observed within each group and to convolve distributions for all groups together, taking into account dispersion in species numerical density suggested by the netting data. However, given uncertainties with the material properties of the zooplankton (uncertainties in $g$ and $h$ ), zooplankton orientations and physiological condition, and the major impacts such variability have on TS, we felt it was overambitious to treat our data in this manner. Rather we were interested in trying to determine whether the magnitude of backscatter from mesozooplankton might serve completely to mask all echoes from jellyfish, and hence to infer whether previously published jellyfish TS estimates were in fact simply measures of the density of the zooplankton community in which the jellyfish were living.

We believe our new data enable us to refute this contention. Despite the fact that we had insufficient data to calculate new TS values, we were encouraged to see that our new data were not inconsistent with our previous, uncorrected data: this provides support for our previously published TS estimates (see Brierley et al. 2001). The objective of this present study was to correct a perceived mesozooplankton-related bias in our previous study. Our conclusion on the basis of the similarity between the present and previous studies is, however, that the previous study was probably not substantially biased by zooplankton. This may seem a surprising conclusion given that the Benguela hosts a rich zooplankton community (Verheye et al. 1992), and that our present study detected densities of zooplankton that in some instances generated substantial echo intensities. However, our conclusion is based upon the fact that jellyfish numerical densities encountered in the present study were substantially lower than those detected using the same sampling approach in our previous study. Previously we detected mean and maximum numbers of Aequorea aequorea per $\mathrm{m}^{3} 10$ and 15 times higher respectively than in the present study (0.4487 cf. 0.0429, and 1.6840 cf. 0.1148), and Chrysaora hysoscella mean and maximum densities 2 and 3 times higher respectively than in the present study (0.0094 cf. 0.0056, and 0.0299 cf. 0.0103). Thus in the previous study absolute echo intensities from jellyfish would have been higher. Furthermore, jellyfish are voracious predators upon zooplankton and we suspect that when our previous study was conducted the very high jellyfish densities may have consumed many zooplankton, depleting standing stocks such that acoustic backscatter from the remaining zooplankton community was less than in the present study. Thus the jellyfish:zooplankton signal-to-noise ratio would have been higher previously than in the present study. Although the contribution from zooplankton in the previous study may have been minor, it was not zero. In fact the $y$ intercepts of all density-intensity regressions determined in the previous study were positive (95\% confidence limits bracketed zero; see Fig. 1), indicating that some backscatter would be expected by these models even under circumstances of zero jellyfish density. If we assume that the positive $y$ intercepts in those models represented the contribution by zooplankton to total backscatter, we can remove those contributions and recalculate TS. Doing this, TS values for $A$. aequorea become $-68.2,-66.7$ and $-72.8 \mathrm{~dB}$ at 18,38 and $120 \mathrm{kHz}$ respectively (cf. $-68.1,-66.3$ and $-68.5 \mathrm{~dB}_{\text {; }}$ Brierley et al. 2001), and for C. hysoscella become $-53.4,-49.0$ and $-52.9 \mathrm{~dB}$ at 18,38 and $120 \mathrm{kHz}$ respectively (cf. $-51.5,-46.6$ and $-50.1 \mathrm{~dB}$ previously). Generally, TS values at higher frequencies are reduced more by this approach than are TS values at low frequencies, and this is consistent with the expectation that backscatter by 'mesozooplankton' will be greater at higher frequencies. Furthermore TS values for $A$. aequorea are reduced less than those for C. hysoscella, suggesting that zooplankton contamination for communities of $A$. aequorea was lower than for C. hysoscella: C. hysoscella is an inshore species and, in the present study, mesozooplankton densities were found to be higher inshore than in the more offshore locations inhabited by $A$. aequorea (801 individual 'mesozooplankton' $\mathrm{m}^{-3}$ inshore compared to $97 \mathrm{~m}^{-3}$ offshore, of which $95 \%$ were copepods). The onshoreoffshore difference in mesozooplankton abundance we observed is consistent with previous studies (Verheye et al. 1992, Sparks et al. 2001). The recalculated TS values are consistent with TS values determined recently from single-target echo detection techniques (Brierley et al. 2004).

Although, frustratingly, we were not able in this present study to generate new TS values for Benguelan jellyfish that explicitly discounted backscatter from non-gelatinous mesozooplankton, the observation that there is no significant difference between mesozooplankton-corrected jellyfish TS and our previously reported TS estimates supports our assertion that jellyfish medusae can be detected acoustically at frequencies used commonly for fisheries surveys. 
Acknowledgements. This study was a research activity under the Benguela Environment Fisheries Interaction and Training Programme (BENEFIT) and the Nansen Programme, funded by the Norwegian Agency for Development Cooperation (NORAD). We thank the Royal Society (UK) for additional funding. We are grateful for the assistance provided at sea by the crew of the FRV 'Dr. Fridtjof Nansen' and A. Gumbo and V. Hashoongo (National Marine Information and Research Centre, Namibia), U. V. Bloemenstein, Z. Boltman and T. Francis (University of Western Cape, South Africa), R. Skeide (Institute of Marine Research, Norway), J. E. Purcell (Shannon Point Marine Center, USA) and L. Hutchings (Marine and Coastal Management, South Africa).

\section{LITERATURE CITED}

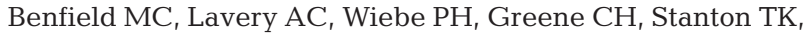
Copley NJ (2003) Distributions of physonect siphonulae in the Gulf of Maine and their potential as important sources of acoustic scattering. Can J Fish Aquat Sci 60:759-772

Brierley AS, Axelsen BE, Buecher E, Sparks CAJ, Boyer H, Gibbons MJ (2001) Acoustic observations of jellyfish in the Namibian Benguela. Mar Ecol Prog Ser 210:55-66

Brierley AS, Axelsen BE, Boyer DC, Lynam CP and 5 others (2004) Single-target echo detections of jellyfish. ICES J Mar Sci 61:383-393

Brodeur RD, Mills CE, Overland JE, Walters GE, Schumacher JD (1999) Evidence for a substantial increase in gelatinous zooplankton in the Bering Sea, with possible links to climate change. Fish Oceanogr 8:296-306

Buecher E, Sparks C, Brierley A, Boyer H, Gibbons M (2001) Biometry and size distribution of Chrysaora hysoscella (Cnidaria, Scyphozoa) and Aequorea aequorea (Cnidaria, Hydrozoa) off Namibia with some notes on their parasite Hyperia medusarum. J Plankton Res 23:1073-1080

Coyle KO (2000) Acoustic estimates of zooplankton biomass and distribution: application of canonical correlation to scaling of multifrequency data. Can J Fish Aquat Sci 57: 2306-2318

Greenlaw CF (1979) Acoustical estimation of zooplankton populations. Limnol Oceanogr 24:226-242

Kideys AE (2002) Fall and rise of the Black Sea ecosystem. Science 297:1482-1484

Lynam CP, Hay SJ, Brierley AS (2004) Interannual variability in abundance of North Sea jellyfish and links to the North Atlantic Oscillation. Limnol Oceanogr 49:637-643

Lynam CP, Heath MR, Hay SJ, Brierley AS (2005a) Evidence for impacts by jellyfish on North Sea herring recruitment. Mar Ecol Prog Ser (in press)

Lynam CP, Hay SJ, Brierley AS (2005b) Jellyfish abundance and climatic variation: contrasting responses in oceanographically distinct regions of the North Sea, and possible implications for fisheries. J Mar Biol Assoc UK 85: $435-450$

Mills CE (2001) Jellyfish blooms: are populations increasing globally in response to changing ocean conditions? Hydrobiol 451:55-68

Pauly D, Christensen V, Dalsgaard J, Froese R, Torres F

Editorial responsibility: Otto Kinne (Editor-in-Chief), Oldendorf/Luhe, Germany
(1998) Fishing down marine food webs. Science 279: 860-863

Pauly D, Christensen V, Guenette S, Pitcher TJ, Sumaila UR, Walters CJ, Watson R, Zeller D (2002) Towards sustainability in world fisheries. Nature 418:689-695

Purcell JE, Arai MN (2001) Interactions of pelagic cnidarians and ctenophores with fish: a review. Hydrobiol 451:27-44

Purcell JE, Decker MB (2005) Effects of climate during 1987-2000 on relative predation by ctenophores and scyphomedusae on copepods in Chesapeake Bay. Limnol Oceanogr 50:376-387

Purcell JE, Sturdevant MV (2001) Prey selection and dietary overlap among zooplanktivorous jellyfish and juvenile fishes in Prince William Sound, Alaska. Mar Ecol Prog Ser 210:67-83

Schneider G, Behrends G (1998) Top-down control in a neritic plankton system by Aurelia aurita medusae-a summary. Ophelia 48:71-82

Skeide R, Engås A, West CW (1997) Multisampler-a new tool for use in sampling trawls. In: Shleinik V, Zaferman M (eds) Seventh IMR-PINRO symposium gear selection and sampling gears. PINRO Press, Murmansk, p 65-76

Sommer U, Stibor H, Katechakis A, Sommer F, Hansen T (2002) Pelagic food web configurations at different levels of nutrient richness and their implications for the ratio fish production: primary production. Hydrobiol 484:11-20

Sparks C, Buecher E, Brierley AS, Axelsen BE, Boyer H, Gibbons MJ (2001) Observations on the distribution and relative abundance of the scyphomedusan Chrysaora hysoscella (Linne, 1766) and the hydrozoan Aequorea aequorea (Forskal, 1775) in the northern Benguela ecosystem. Hydrobiol 451:275-286

Stanton TK (1989) Simple approximate formulas for backscattering of sound by spherical and elongated objects. J Acoust Soc Am 86:1499-1510

Stanton TK, Wiebe PH, Chu D, Benfield MC, Scanlon L, Martin L, Eastwood RL (1994) On acoustic estimates of zooplankton biomass. ICES J Mar Sci 51:505-512

Stanton TK, Chu DZ, Wiebe PH (1996) Acoustic scattering characteristics of several zooplankton groups. ICES J Mar Sci 53:289-295

Trevorrow MV, Tanaka Y (1997) Acoustic and in situ measurements of freshwater amphipods (Jesogammarus annandalei) in Lake Biwa, Japan. Limnol Oceanogr 42: 121-132

Verheye HM, Hutchings L, Huggett JA, Painting SJ (1992) Mesozooplankton dynamics in the Benguela ecosystem, with emphasis on the herbivorous copepods. S Afr J Mar Sci 12:561-584

Watkins JL, Brierley AS (1996) A post-processing technique to remove background noise from echo integration data. ICES J Mar Sci 53:339-344

Wiebe PH, Mountain DG, Stanton TK, Greene CH, Lough G, Kaartvedt S, Dawson J, Copley N (1996) Acoustical study of the spatial distribution of plankton on Georges Bank and the relationship between volume backscattering strength and the taxonomic composition of the plankton. Deep-Sea Res II 43:1971-2001

Xian W, Kang B, Liu R (2005) Jellyfish blooms in the Yangtze Estuary. Science 307:41

Submitted: October 26, 2004; Accepted: March 13, 2005

Proofs received from author(s): June 6, 2005 